\title{
Systematic review and meta-analysis of lactose digestion, its impact on intolerance and nutritional effects of dairy food restriction in inflammatory bowel diseases
}

\author{
Andrew Szilagyi ${ }^{1^{*}}$ (D) Polymnia Galiatsatos ${ }^{1}$ and Xiaoqing $X^{2}$
}

\begin{abstract}
Background: Relationships between inflammatory bowel disease and lactose containing foods remain controversial and poorly defined regarding symptoms, nutritional outcomes, and epidemiologic associations for lactose maldigestion.

Methods: A literature review was performed using Pub Med, Cochrane library and individual references, to extract data on lactose maldigestion prevalence in inflammatory bowel diseases. A meta-analysis was done using selected articles, to determine odds ratios of maldigestion. Information was collected about symptoms, impact on pattern of dairy food consumption, as well as the effects of dairy foods on the course of inflammatory bowel diseases.

Results: A total of 1022 articles were evaluated, 35 articles were retained and 5 studies were added from review articles. Of these 17 were included in meta-analysis which showed overall increased lactose maldigestion in both diseases. However increased risk on sub analysis was only found in Crohn's in patients with small bowel involvement. Nine additional studies were reviewed for symptoms, with variable outcomes due to confounding between lactose intolerance and lactose maldigestion. Fourteen studies were evaluated for dairy food effects. There was a suggestion that dairy foods may protect against inflammatory bowel disease. Nutritional consequences of dairy restrictions might impact adversely on bone and colonic complications.

Conclusions: Lactose maldigestion in inflammatory bowel disease is dependent on ethnic makeup of the population and usually not disease. No bias of increased disease prevalence was noted between lactase genotypes. Intolerance symptoms depend on several parameters besides lactose maldigestion. Dairy foods may decrease risks of inflammatory bowel disease. Dairy restrictions may adversely affect disease outcome.
\end{abstract}

Keywords: Lactose malabsorption, Intolerance, Inflammatory Bowel Diseases

\section{Introduction}

The Inflammatory Bowel Diseases (IBD), Crohn's Disease (CD) and Ulcerative Colitis (UC), are complex conditions with enigmatic causes. Pathogenesis implicates interactions between a genetically susceptible host and a disturbed bacterial microflora resulting in aberrant innate and adaptive immune responses [1]. The intestinal microflora is responsive to various factors such as antibiotics

\footnotetext{
* Correspondence: aszilagy@jgh.mcgill.ca

${ }^{1}$ Division of Gastroenterology, Department of Medicine, Jewish General Hospital, Room E-110,3755 Cote Ste Catherine Rd, Montreal, QC H3T 1E2, Canada

Full list of author information is available at the end of the article
}

and diet $[2,3]$. In IBD, diet may be important both for pathogenesis and nutrition [4-6], although specific proof is lacking for the former [7].

The role of dairy foods (DFs) in IBD has been controversial and confounded by the phenotypic divide of lactase status in the adult population. About $1 / 3$ of adults retain the ability to digest lactose (LP; lactase persistence, lactose digesters) while the rest lose it (LNP; lactase non -persistence, lactose maldigesters $[\mathrm{LM}])$. The links between lactose, milk, DFs and IBD are topics related on several levels. The world segregation into LP /LNP correlates with a number of diseases, including IBD, raising the question of a coincidental event or an 
evolutionary modifier of disease similar to latitudinal distributions [8]. As such, unequal phenotype distributions of LP/LNP in IBD may be an additional risk factors for IBD [9] or may predispose to LM. Patients with IBD may find that DFs aggravate their symptoms, leading them and some professionals to recommend a reduced lactose diet [10]. In healthy persons milk and other DF avoidance is partly related to true lactose intolerance (LI) or the presumption of LI due to suggestive symptoms $[11,12]$. However symptoms from diet are also affected by consumption of Fermentable Oligo, Di, Monosaccharide And Polyols (FODMAPs) in IBD [13, 14]. Lactose is generally excluded in a low FODMAP diet independent of lactose digestion status.

It also remains unclear what role DF avoidance has on nutritional effects on patients with IBD. This systematic review seeks primarily to determine the prevalence of LM in IBD and establish whether there is a bias toward either phenotype. Secondary outcomes were determining whether symptoms of LI play a role in DF avoidance, and whether DF restriction impacts on IBD course.

\section{Methods}

\section{Search strategy}

A review of the literature between Jan 1965 to June 2016 was undertaken. The search engines Medline (Pub Med) and Cochrane Library were used to obtain relevant articles. Terms used were lactose maldigestion or lactose intolerance or milk intolerance or lactose sensitivity (LI with systemic symptoms) AND Inflammatory Bowel Disease or Crohn's disease or Ulcerative colitis. In the case of the Cochrane library, the terms "systematic review" or "metaanalysis" were also selected, to narrow the search. Two authors (AS and PG) independently evaluated articles for inclusion in meta-analysis and disagreement was settled by consensus. A second search for articles was also included with the terms nutritional benefits OR detriments of milk OR dairy products in Inflammatory Bowel Disease, Chrohn' disease Or Ulcerative colitis. References of individual review articles were also screened for relevant publications.

\section{Definitions}

For the purpose of meta-analysis a clear distinction was made between objective tests of LM vs. symptoms attributed to LI or sensitivity. The reasons for this are that LI is subjective and can occur in the absence of LM and symptoms elicited during lactose challenge tests do not necessarily reflect reactions to DF ingestion. The term lactose tolerance test (LTT) retains the name but an abnormal test suggests LM and LI may occur as with the hydrogen breath test (BT). Small bowel biopsies, urinary sugar tests or genetic tests define the propensity for LM but do not predict symptomatic LI.
Article eligibility for meta-analysis or nutritional effects Original articles and case reports (including more than 5 patients) were included if patients underwent objective testing for lactose digestion (regardless of method), and if they were compared to a healthy control group. Abstracts in English were included if sufficient data were available from the report. Articles including patients with other diseases but no IBD were excluded from analyses. For the second outcome, looking at prevalence of symptoms of LI in IBD, articles referring to LI, or DF intolerance or sensitivity were also sought, regardless of formal testing for lactose digestion. For nutritional impact, studies investigating DF effects or general diet on IBD were sought. The latter had to include reference to milk or DFs. Additional references were manually extracted from review articles on the topic.

\section{Data extraction for meta-analysis}

Year of publication, country of origin, number of patients and controls, type of test for LM, test outcomes, distribution of $\mathrm{CD}$ or UC cases, site of involvement in $\mathrm{CD}$, disease activity at time of testing, and surgical history were recorded from each study. A description of genetic likelihood of LM for patients versus controls was estimated. Each study included in the meta-analysis was graded by country for low (= grade $1, \leq 20 \%$ LNP), moderate (= grade 2, $21-79 \%$ LNP), or high risk (=grade 3, LNP $\geq 80 \%$ ), based on classification as per Mishkin [15] and Szilagyi [9].

\section{Quality assessment}

Articles included in the meta-analysis were graded based on the Newcastle Ottawa scale for case control studies [16]. In this scheme, high quality studies achieved a score of 5 or more, and scores of 4 or less were considered low quality. Abstracts were not graded. PRISMA guidelines were followed [17].

\section{Data analysis}

For each study, two by two tables of LM status (LM vs. not-LM) and IBD status (IBD vs. healthy control) were obtained. For studies with a zero cell, a continuity correction of 0.5 was used [18]. The association between LM and IBD were assessed using odds ratios (OR) and the corresponding $95 \%$ confidence intervals (CIs). An OR greater than 1.0 indicates an increased risk of LM among IBD group compared with the healthy control group. The statistical significance of the summary OR was determined with the $\mathrm{Z}$ test, and a $p$-value less than 0.05 was considered statistically significant.

The heterogeneity among studies was determined by the Cochran $\mathrm{Q}$ statistics, where a $p$-value greater than 0.05 indicates a lack of heterogeneity. The $I^{2}$ statistics were also presented [19]. For the qualitative interpretation 
of heterogeneity, $I^{2}$ values of at least $50 \%$ are usually considered to represent substantial heterogeneity, while values of at least $75 \%$ indicate considerable heterogeneity according to the Cochrane Handbook. The summary OR was obtained using a fixed-effect model (Mantel-Haenszel method) when there was a lack of heterogeneity $\left(I^{2} \leq 50 \%\right)$, or a random-effects model (the DerSimonian and Laird method) when otherwise [20, 21]. The potential publication bias was estimated by a funnel plot for the overall analysis. Egger's linear regression test on the natural logarithm scale of the OR was used to assess the funnel plot asymmetry; the significance was set at the $p<0.05$ [22].

Sensitivity analysis was performed according to the following subgroups: type of IBD (CD or UC), specific disease site in the case of $\mathrm{CD}$ (SB-small bowel only, TiCTerminal ileum and Colon, DC-colon only); type of test (BT-Breath Hydrogen measurement, LTT-Lactose tolerance test, urinary sugar ratios and small bowel biopsies); and finally evaluation of LM among the low risk group. The purpose of analyzing low risk group separately was that any disease effect involving intestinal lactase levels would be more likely to be detected in this group. All analyses were performed using SAS statistical package, version 9.1 (SAS Institute Inc., Cary, NC, USA).

\section{Results}

The first search yielded a total of 570, while the complementary search yielded an additional 452 publications during the specified time period. Of the combined 1022 articles, 35 studies were retained, as per inclusion/exclusion criteria. Seventeen of these were included in the meta-analysis of prevalence of LM. Nine of 35 additional papers without controls, discussion of methodology or DF related symptoms were included for narrative review. Nine of 35 studies were included in a review of nutritional effects of DFs. A further 5 were added to these 9 after manual extraction from general diet review articles in IBD for a total of 40 papers (Fig. 1).

\section{Prevalence of lactose maldigestion in IBD Description of included studies for meta-analysis}

The meta-analysis included a total of 1935 IBD patients (560 CD, 614 UC) and 761 controls. Table 1 outlines demographics of 17 studies (23 - 38). The mean age of participants based on available data was 35.6 years for $\mathrm{CD}, 40.8$ years for UC, and 37.7 years for controls. One study focused exclusively on a pediatric population (mean age 13.5, range of 5-18) [30]. Based on reports that specified gender distribution, there were more females in the IBD groups than the control group.

Eleven studies originated from countries with low risk for LNP [15, 23-32] and 4 specified ethnic make-up [15, 27, 30, 31]. Five reports were from moderate risk countries [33-37] and 1 was from a high risk country [38].

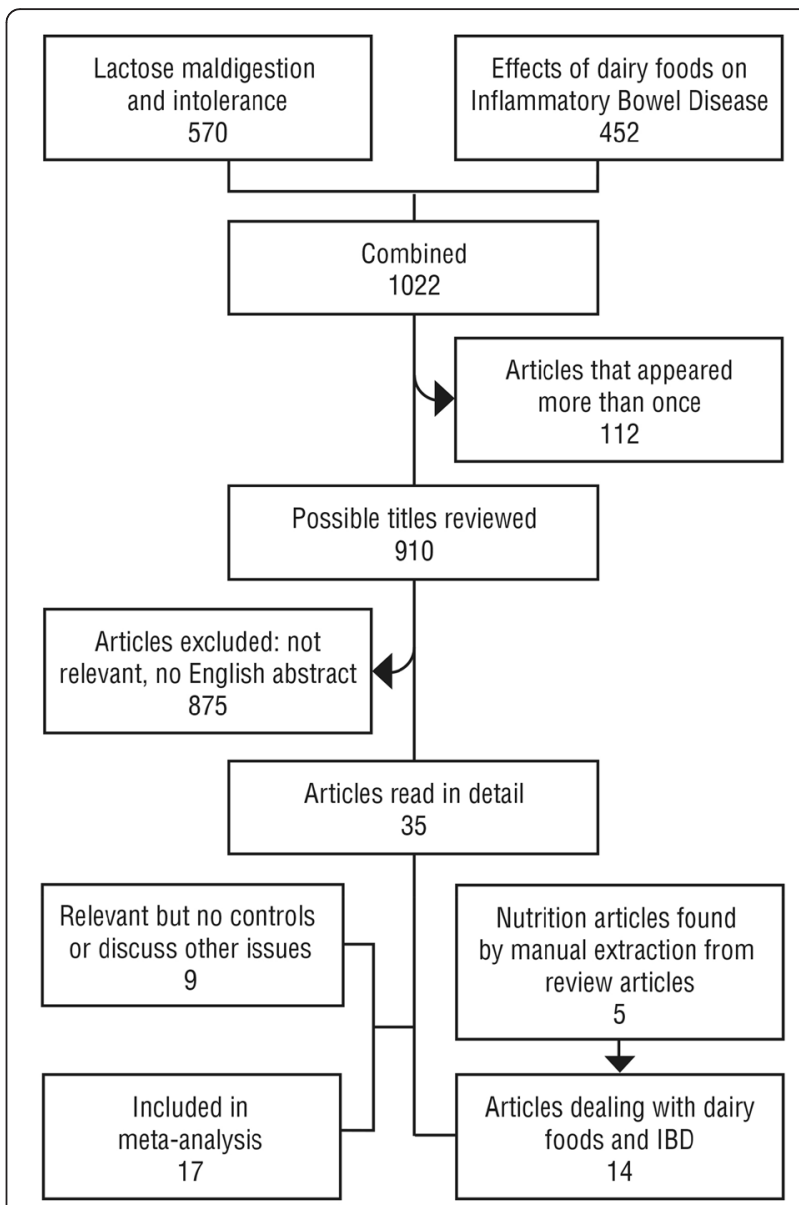

Fig. 1 The outline for flow of retrieved articles

Twelve studies used a lactose challenge with measurement of BT [15, 24-27, 30, 33-38]. One of these also analyzed the C/T-13910 polymorphisms [24]. Two studies used LTT alone [31, 32]. Two evaluated jejunal biopsies $[23,28]$ and one used urinary lactose/L-arabinose sugar ratio to define LM [29]. Intestinal biopsies [39], BT and the LTT have been validated against genetic tests for the north European C/T- 13910 lactase polymorphisms [40].

\section{Outcome of meta-analyses}

The OR for LM in IBD vs. in controls including the 4 indirect tests was 1.61 (95\% CI: $1.00-2.57), p=0.048$. Heterogeneity was substantial at $\mathrm{I}^{2}=69.3 \%$. In subgroup analyses, for $\mathrm{CD}$ specifically the outcome was still statistically significant with an OR of 2.29 (95 \% CI:1.09-4.80, $p=0.03, \mathrm{I}^{2}=74.8 \%$ ), but did not reach statistical significance for $\mathrm{UC}(\mathrm{OR}=1.14,95 \% \mathrm{CI}: 0.69-1.86, p=0.62$, $\mathrm{I}^{2}=53.8 \%$ ). Fig. 2 shows the forest plots with $\log \mathrm{OR}$ using all type of tests.

Subgroup analysis using BT alone showed similarly that LM was only significant in CD $(\mathrm{OR}=2.35,95 \%$ 
Table 1 Studies of lactose maldigestion in IBD using breath test, lactose tolerance test, jejunal biopsies or urinary sugar ratio tests

\begin{tabular}{|c|c|c|c|c|c|c|c|c|c|}
\hline Author (reference) County & Activity of disease & Test Method & Age (female \%) & $C D N / L M$ & Age (female \%) & UC N/ LM & Age (female \%) & $\begin{array}{l}\text { Control } \\
\mathrm{N} / \mathrm{LM}\end{array}$ & NOS Score \\
\hline Gupta [33] India & 1 & BT & $34.7(26)^{a}$ & $27 / 10^{a}$ & 36.2 & $18 / 10^{a}$ & $36.2(26)^{a}$ & $45 / 12$ & 7 \\
\hline Eadala [24] Wales UK & $\mathrm{k}^{\mathrm{c}}$ & BT Gen & 19-86 (38) & $70^{d} / 2^{b}$ & $20-81(44)$ & $95 / 11^{\mathrm{b}}$ & $21-56(15)$ & $30 / 0$ & 8 \\
\hline Barrett [25] Australia & $1^{c}$ & BT & $40(56)$ & $92^{d} / 39$ & $40(44)$ & $56 / 22$ & $34(20)$ & $71 / 13$ & 9 \\
\hline Banos Madrid [34] Spain & nd & BT & nd & $18 / 3$ & nd & $24 / 4$ & nd & $25 / 5$ & 7 \\
\hline Ginard [35] Spain & nd & BT Quest & nd & nd & $40(32)$ & $52 / 13$ & $41(20)$ & $34 / 11$ & 7 \\
\hline Von Turpitz [26] Germany & $24 \mathrm{~A} 25 \mathrm{I}^{\mathrm{C}}$ & BT Bx & $39.9(30)$ & $49 / 16$ & nd & nd & $43.1(11)$ & $24 / 5$ & 6 \\
\hline Mishkin [15] Canada ${ }^{f}$ & $\mathrm{I}^{\mathrm{c}}$ & BT & $36.9(62)$ & $121^{d} / 70$ & $37(71)$ & $139 / 65$ & nd nd & $158 / 46$ & 8 \\
\hline Bernstein [27] Canada ${ }^{f}$ & $18 \mathrm{~A} 111$ & BT Quest & nd & nd & $39(13)$ & $29 / 13$ & $41(4)$ & $14 / 5$ & 8 \\
\hline Kochlar [36] India & $22 \mathrm{~A} 381$ & BT & nd & nd & $36.7(35)$ & $60 / 25$ & $36.4(7)$ & $20 / 8$ & 7 \\
\hline Ogata [38] Japan & nd & BT LTT & nd & 32/29BT32/30LTT & nd & nd & nd & 51/26BT51/37LTT & nd \\
\hline Park [28] Scotland & $21 \mathrm{~A} 411$ & $\mathrm{Bx}$ & $40(38)$ & $62^{d}$ & nd & nd & $40(9)$ & 13 & 5 \\
\hline Lobely [29] England & nd & USR & $42 \mathrm{nd}$ & 16 & 42 (nd) & 6 & $28.5(13)$ & 40 & 6 \\
\hline Pironi [37] Italy & $\mathrm{I}^{\mathrm{c}}$ & BT & $33(23)$ & $37 / 18$ & nd & nd & $35(36)$ & $67 / 11$ & 7 \\
\hline Kirschner [30] United States ${ }^{f}$ & $37 A^{9} 331$ of IBD & BT & 13.5 (nd) & $50 / 17$ & 13.5 (nd) & $20 / 5$ & nd (nd) & 42 & 7 \\
\hline Pena [23] England & 37A 35I & $\mathrm{Bx}$ & nd & nd & nd & $72 / 9$ & nd & $21 / 2$ & 6 \\
\hline Tandon [31] United States ${ }^{f}$ & nd & $\mathrm{LTT}$ & nd & nd & nd & $70^{e}[51 / 12][19 / 16]$ & nd & $94^{e}[53 / 11][41 / 29]$ & 7 \\
\hline Chalfin [32] United States & nd & LTT & $40.8(2)$ & $5 / 3$ & $42.8(5)$ & $9 / 4$ & $44.3(7)$ & 12 & 5 \\
\hline
\end{tabular}

$B T$ breath hydrogen test, $L T$ lactose tolerance test, $B x$ jejunal biopsy, USR urinary sugar ratio(lactose/L-arabinose), Gen Genetic test for north European lactase polymorphism C $T$-13910, Quest questionnaire, $L M$ lactose maldigestion, LA lactose absorption, nd-not done or not stated, $I$ inactive disease, $A$ active disease

a Gupta reported $L M \%$ and gender distribution in IBD vs Control

${ }^{b}$ Eadala reported breath tests in the bracketted space and genetic test results in the primary listed numbers, CC is the genotype for lactase non persitence from the C/T-13910 north European polymorphism

'Included information on previous surgery in Crohn's disease. Mishkin reported no effect of surgery on LM. In these reports only Eadala reported a single patient after colectomy for ulcerative colitis

${ }^{\mathrm{d}}$ Studies which included enough data on site of disease in CD and frequency of lactose maldigestion

'This study evaluated Jewish and non Jewish patients and controls

Studies specifying ethnic make-up of patients and controls

${ }^{9}$ Kirschner et al. reported no effect of activity on LM 
a

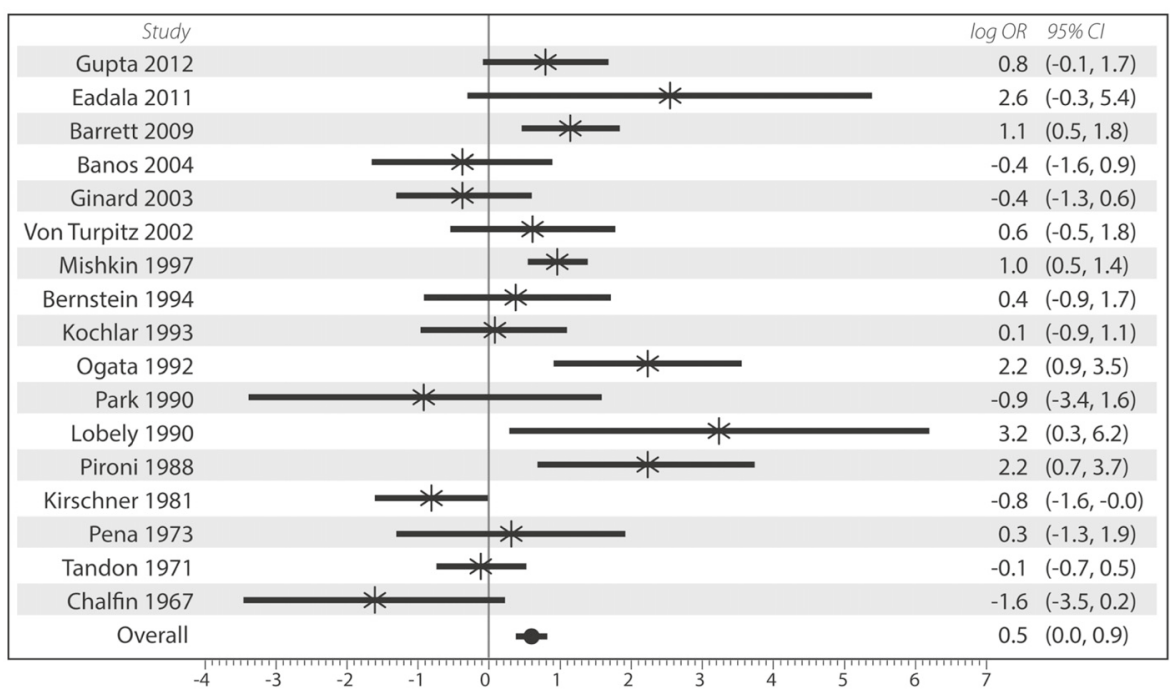

b

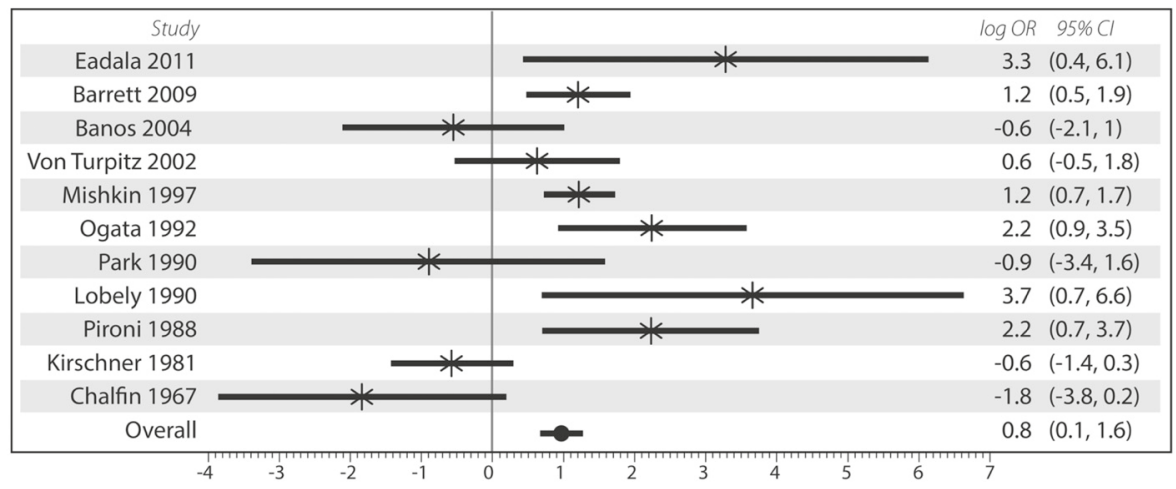

C

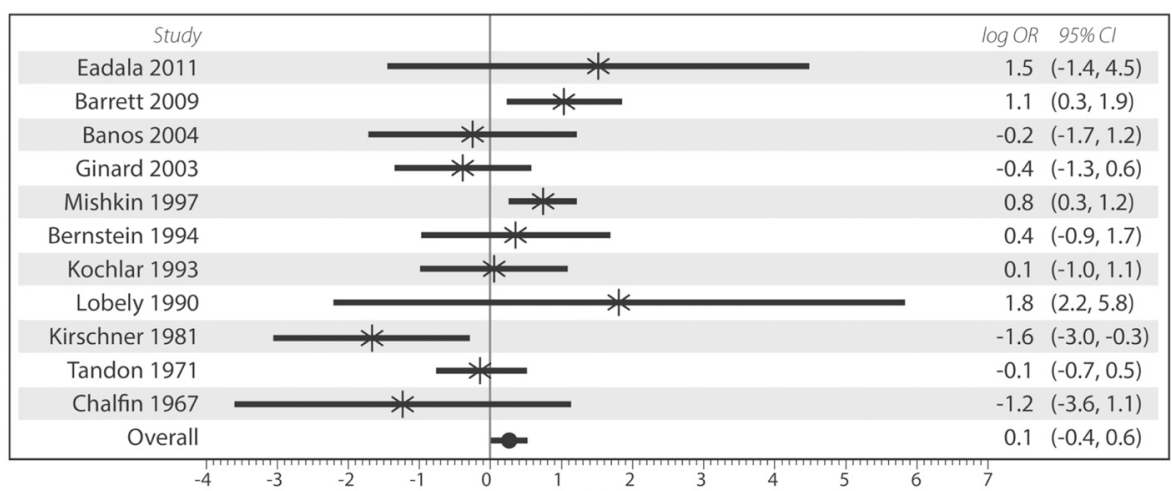

Fig. 2 a Forest plot of 17 articles which evaluated indirect tests of lactose maldigestion in patients with inflammatory bowel diseases compared with controls. The 4 indirect tests were the hydrogen breath test, lactose tolerance test proximal small bowel biopsy and sugar urinary ratio test. b Forest plot of 11 studies evaluating only Crohn's disease using all type of tests. c Forest plot of 11 studies evaluating only ulcerative colitis using all type of tests 
CI:1.21-4.57, $\left.p=0.012, \mathrm{I}^{2}=74.1 \%\right)$, but not in UC $\left(\mathrm{OR}=1.21,95 \% \mathrm{CI}: 0.67-2.18, p=0.53, \mathrm{I}^{2}=59.8 \%\right)$. Fig. 3 shows the forest plots with log OR using breath test only. LTT did not show any statistically significant differences in CD $(n=2$ studies, OR $=1.0 \quad(95 \%$ CI:0.03-33.3)) or UC ( $n=2$ studies, OR $=0.84(95 \%$ CI:0.46-1.54)) [data not shown].

Sub-analysis of $C D$ sites were analyzed in relation to $\mathrm{SB}, \mathrm{TiC}$ or Colon. When all populations were included, site impact was not significant [SB: $\mathrm{OR}=2.53(95 \% \mathrm{CI}$ : 0.45 - 14.3); TiC: OR=1.42 (95 \% CI:0.35 - 5.83); Colon: $\mathrm{OR}=1.42$ (95\% CI:0.82 - 2.46)], based on 5 studies $[15,24,25,28,30]$. However, when low risk populations were analyzed independently, $\mathrm{SB}$ and $\mathrm{TiC}$ sites were significantly associated with LM whereas Colon was not [SB: OR=6.2 (95\% CI:1.01 - 35.1), $p=0.039$, $\mathrm{I}^{2}=65.3 \%$; TiC: $\mathrm{OR}=4.2(95 \% \mathrm{CI}: 2.26-7.66), p<$ $0.0001, \mathrm{I}^{2}=49.1 \%$; Colon: $\mathrm{OR}=1.01$ (95 \% CI:0.49 2.06), $p=0.307, \mathrm{I}^{2}=16.8 \%$ ] [15, 24, 25, 28] (Fig. 4).

The effect of disease activity on LM status was conflicting, with some studies showing an effect [23, 26, 36], while another showed no effect in either UC nor CD [30]. Surgical history was not found to affect LM status in CD [15].

No publication bias was detected for the combination of all tests in IBD $(p=0.91)$, or individual papers on CD $(p=$ $0.89)$ or UC $(p=0.37)$ using Egger's test. No publication bias was detected for low-risk group CD tests $(p=0.51)$.

\section{Description of studies not included in meta-analysis}

There were a total of 9 studies of LM or LI that were excluded from the meta- analysis because no specific controls were provided. Outcomes were compared to nationally recognized frequency of LNP status or they described other aspects of tests [41-49]. Wiecke et al. examined jejunal biopsies from 65 children [mean age 14 range 3-18 years] with a number of gastrointestinal diseases and found low lactase levels in IBD, however these similar to national expectations [30-35 \% LNP] [41]. In a large number of patients who underwent BT, Huppe et al. found the frequency of LM in 124 CD patients to be comparable with population data, but failed to explore effects of site, disease activity or resection extent on LI/LM. In 53 UC patients LM rates were significantly lower [3.8 \% vs about $20 \%$ of the German population] [42]. This finding was also reported by Mishkin et al. [15]. In a double-blind crossover study of 39 UC patients, BT outcomes were similar to Mexican population rates [46 \% vs about $50-70 \%$ ] [43]. In 2 studies from Denmark, (national LM prevalence, 5-6 \%), performance of an LTT showed no difference from expected rates [6 \% CD, $9 \% \mathrm{UC}][44,45]$. However one reported higher LM rates with activity of IBD [44], while the other found no relationship other than ethnic distribution in UC patients [45]. Nevertheless a lactose free diet seemed to benefit patients without proof of LM [44].

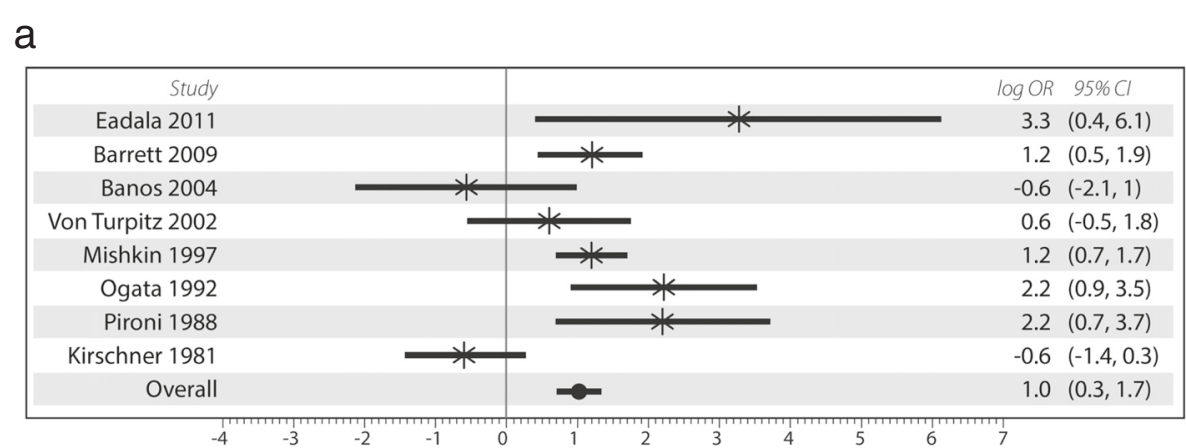

b

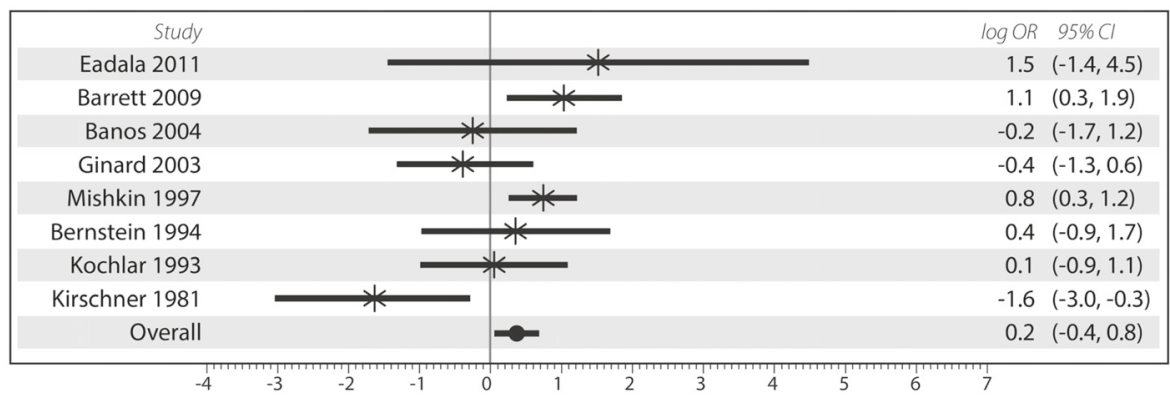

Fig. 3 a Forest plot of 8 studies evaluating only Crohn's disease using breath test. $\mathbf{b}$ Forest plot of 8 studies evaluating only Ulcerative colitis using breath test 


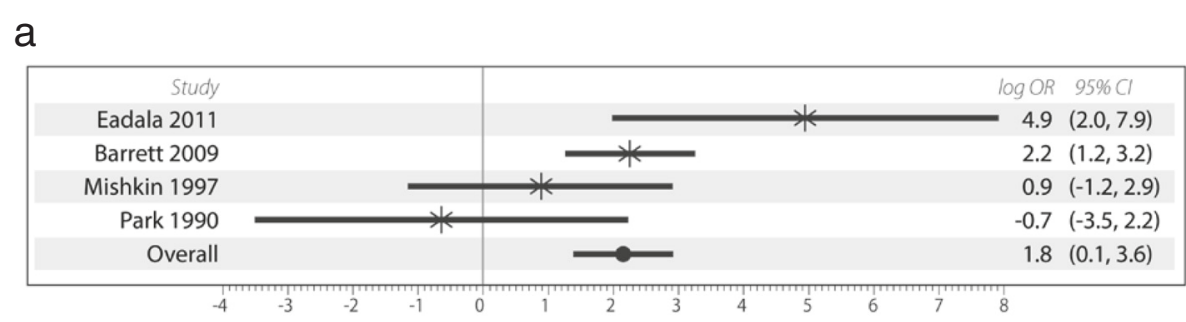

b

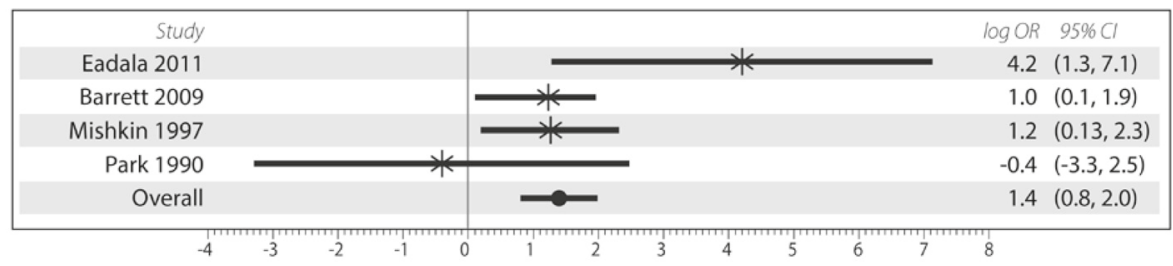

C

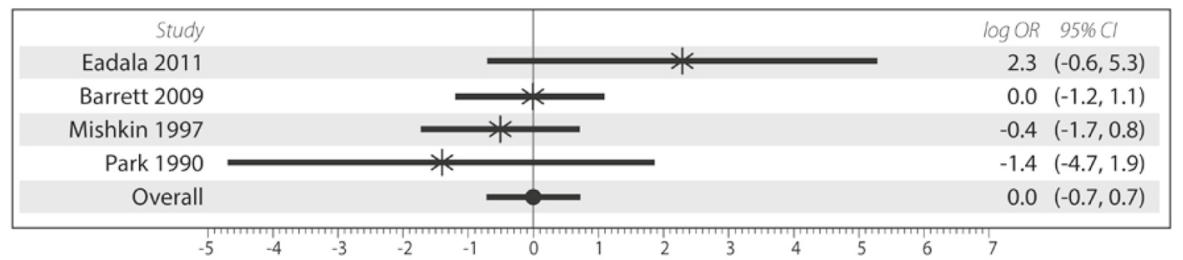

Fig. 4 Forest plots of studies which divided Crohn's disease patients by site of dominant disease using any test and including patients only from low risk for lactase non persistent status compared with healthy controls. Figure $\mathbf{a}$, represents analysis of small bowel only, Figure $\mathbf{b}$ represents analysis of terminal ileum and colon, Figure c represents colon only

Three other studies were identified. In one, concentrations of urinary lactose/raffinose were increased in $19 \%$ of $\mathrm{CD}$ patients but no other specific details were given [46]. Two, studies reported outcomes of jejunal biopsies. Dunne et al. reported that small bowel concentrations of lactase and brush border surface were reduced in patients with $\mathrm{CD}$, while levels in UC were comparable to controls [47], This was confirmed in another study of UC patients [48]. One study addressed symptoms only but these were not lactose related [49].

\section{Milk and lactose intolerance and lactose sensitivity}

Thirteen studies (excluding those dealing with nutrition because they describe different aspects) alluded to symptoms of milk or lactose intolerance [MI and LI respectively], [24, 26, 27, 30, 31, 33-37, 42, 44, 49]. In 7 of these, the terms LI and LM were interchangeable suggesting that symptoms during testing might reflect daily LI $[27,30,31,33,34,36,42]$. In 4 studies LI was used to define LM [27, 34, 36, 42]. LI and LM were more frequent in pancolitis than in left-sided colitis or proctitis, and more with disease activity [36]. LI occurred more frequently with small bowel $\mathrm{CD}$ or higher loads of lactose [37]. In 2 studies, MI was higher in CD [26] or UC [27] than in controls. However the rate of MI correlated with duration of disease rather than location, or resection length in CD [26].

Dissociation between LI and LM was noted in 5 studies $[24,26,27,33,37]$. In particular Eadala et al. noted a discrepancy between the frequency of genetic LNP in patients and controls compared with the prevalence of lactose sensitivity which reached $70 \%$ in IBD [24]. They also noted a discrepancy between the results of genetic tests and BT, with positive BT tests occurring more frequently in patients. This observation was also noted by Barrett et al. [25], where ileal disease produced more frequent positive tests than ileocolic or colonic involvement. Pironi et al. recorded more frequent LM in operated CD compared with controls yet LI occurred in only 3 of 11 patients with operations [37].

\section{Articles dealing with nutritional impact of dairy foods}

A total of 14 articles were reviewed primarily for nutritional effects [50-63]. Descriptions of these publications are presented in Table 2. Two were epidemiological, showing a rise in incidence of IBD correlating with rising consumption of western type diet, particularly animal protein including DFs $[50,51]$. In 2 cross sectional studies, consumption of $1.25 \mathrm{~L}$ of milk /week was beneficial in reducing symptoms in UC [52] while milk and yogurt reduced risk of $\mathrm{CD}$ in another study [53]. A 
Table 2 Studies reporting on the impact of dairy foods on inflammatory bowel diseases (IBD). DF = dairy food, Inc = incidence

\begin{tabular}{|c|c|c|c|c|c|c|}
\hline Author & Type of Study & Crohn's Disease (N) & Ulcerative Colitis (N) & IBD (N) & Healthy Control (N) & Outcome \\
\hline Kitahora [50] & Epidemiology & - & 10819 & - & - & Positive correlate. with UC inc \\
\hline Shoda [51] & Epidemiology & 292 & - & - & - & Inc high correlate with DF in univariate analysis \\
\hline Magee [52] & $\begin{array}{l}\text { Prospective } \\
\text { Cross-section }\end{array}$ & - & 81 & - & - & $1250 \mathrm{ml} /$ week protective \\
\hline Octoratou [53] & Prospective Cohort & 28 new 30chronic & - & - & 38 & Milk and yogurt protective \\
\hline Abubakar [54] & Case-control & 218 & - & - & 812 & Drinking pasteurized milk protects \\
\hline Opstelten [55] & Cohort & 110 & 244 & - & 401,326 & $\begin{array}{l}\text { DF protect CD } 0.3 \mathrm{Cl}(0.13-0.65) \text { UC diagnose } \\
>3 \text { years Significant trend } 0.04\end{array}$ \\
\hline Spehlmann [59] & Twin Study & - & - & 512 Twins 1 with disease & 207 and (392 non twin IBD) & DFs no effect \\
\hline Jantchou [57] & Prospective Cohort & 33 & 43 & - & 67504 & DF no effect. Animal protein + correlate \\
\hline Reif [58] & Case-control & 33 & 54 & - & 144 & Pre Disease no effect of lactose \\
\hline Jowett $^{\mathrm{a}}[56]$ & Prospective Cohort & - & 183 (52\% relapse) & - & - & $\begin{array}{l}\text { No effect } 1.17 \mathrm{Cl} 0.53-2.5 \text { Medium intake no } \\
\text { effect with high intake }\end{array}$ \\
\hline Joachim [60] & Prospective Cross-section & 33 & 27 & - & - & DFs prominent in relapse \\
\hline Jowett [61] & Prospective Cohort & - & 183 (52 \% relapse) & - & - & $68 \%$ diet thought important, most restricted DFs \\
\hline Vernia [63] & Case-control & 91 & 96 & - & 420 and (276 other diseases) & $\begin{array}{l}\text { Females with } C D \text { and } U C \text { had significantly lower } \\
\text { Ca intake than recommended }\end{array}$ \\
\hline Brazil Lopes [62] & Cross Section & 21 & 44 & - & - & $64.7 \%$ restricted DFs \\
\hline
\end{tabular}

Jowett et al. published 2 papers on the same population. One showing no impact of Dfs on UC and the second evaluated patients' beliefs on effects of diet on UC 
prospective study suggested that pasteurized milk reduced risk for CD [54]. The most recent and largest prospective cohort study supported the observation that the highest quartile of milk intake significantly reduced $C D$ risk. There was also an overall significant trend for reduced $\mathrm{UC}$ if data were analyzed 3 years after commencement of the study [55]. Four studies with different methodologies evaluating DFs among a general diet in IBD, did not find any statistically significant impact [56-59]. Four studies used questionnaires with different intended outcomes regarding role of DFs in IBD. One reported increased flares with DFs [60], while 3 reported reduced intake of milk and DFs [61-63]. In the report by Jowett restrictions were supported by professional advice [61] while symptomatic, active IBD patients were more likely to withhold DFs in another study [62].

From papers reviewed for lactose maldigestion, Gupta et al. found that despite similar rates of LM, IBD patients restricted DFs [33]. Bernstein et al. noted that DF restriction by UC patients or physician advice was based solely on presence of disease [27]. Finally in a large study of CD patients, it was argued that a high fat content in DFs is likely the source of symptoms [49]. Self-reported $\mathrm{LI}$ and active disease were the most important patient reported reasons for DF restriction [24, 49, 62, 63].

Dietary advice included a milk free diet in UC, regardless of LM status [44]. Two suggested.

DF restriction with disease activity only [26, 36]. Five suggested to restrict if positive LM status is established $[23,28,35,41,48]$, while 4 suggested that there was no need to restrict DFs in IBD at all [24, 27, 37, 49].

\section{Discussion}

Relationships between IBD and DF suggest that rates of LM largely reflect ethnic backgrounds of patients. Activity of IBD and small bowel involvement in CD increases LM rates. Symptoms of LI during tests may not reflect daily DF reactions. Consequences of true or self perceived LI may impact on DF consumption which may have variable outcomes.

\section{Lactose maldigestion in IBD}

In the mid 20th century, milk protein allergy was considered a possible cause of UC [64]. As well in the early 1960s reports emerged showing that intestinal lactase levels were diminished in UC and were accompanied by self-restricted and physician-advised reduction of DFs in IBD $[65,66]$. The impact of ethnicity was not yet proven.

The meta-analysis on LM rates does show a statistically significant increase in prevalence. However, analysis of $\mathrm{CD}$ and $\mathrm{UC}$ independently reveals that the outcome is driven by $C D$ with small bowel $C D$ involvement. Sub analysis of BT also follows the overall pattern suggesting that LM is either secondary to mucosal disease, motility disorder or bacterial overgrowth not necessarily genetics [67]. In other cases ethnic distributions account for the frequency of LM. These results should be interpreted with some caution in light of moderate or high heterogeneity encountered.

The notion that IBD rates differ between LP and LNP populations rests on epidemiological correlations between IBD and population distributions of LP and LNP [8]. The outcome of the meta-analysis suggests that LP and LNP persons may be equally affected by IBD.

There are only few studies examining possible risks of different lactase alleles in IBD. Eadala et al. evaluated C/ T-13910 polymorphism in a group of patients from Wales and found a $6 \%$ rate of CC (LNP) genotype among 165 Welsh IBD patients [24]. This frequency is close to the national rate. Earlier reports were conflicting however. Buning et al. did not find any statistically significant differences in frequency of IBD among German patients with CC genotype [68]. Elguezabal et al. could not confirm increased TT/CT genotypes in Spanish patients [69]. However an earlier study from Spain [70] and one from New Zealand [71] did find increased prevalence of Crohn's disease in TT genotype (LP phenotype) persons.

The current observations however can't rule out different rates or delay in disease development between LP and LNP. For example IBD rates are different between Indigenous populations and Caucasians described both in Canada [72] and New Zealand [73]. In both areas Indigenous people are predominantly LNP and Caucasians are predominantly LP.

\section{Symptoms of LI}

It is no longer accurate to equate LI with LM. The reason for this is that studies of LI in patients with irritable bowel syndrome (IBS) showed similar frequency of symptoms whether they were LNP or LP phenotype $[74,75]$. Another reason is the ability of LNP persons to adapt to continued lactose consumption [76]. Lactose in LNP/LI persons induces symptoms (LI) through a metabolic effect on the microbiome [77]. In LNP persons, continued ingestion of sufficient lactose will lead to microbiome adaptation resulting in altered metabolomes as well as reduced test outcomes for BT [78].

However ability to adapt to lactose in IBD is unclear and there are no formal trials. Using lactulose, a disaccharide with similar properties to lactose failed to show adaptation compared with healthy controls [79]. Pironi et al. however may have detected microbial adaptation since despite increased LM status only $8 \%$ of CD patients were also LI [37].

There are two other factors which may alter symptoms to lactose/DFs. As in the case of the study by Nolan -Clark, DFs containing fats may actually be the prime cause of symptoms [49], a possibility also stressed by Mishkin [12]. 
As well, a role of FODMAPs driving food sensitivities needs to be considered [80]. Restriction of these may reduce symptoms in IBD [81], since irritable bowel syndrome is frequent in IBD even in remission [82]. However, in this paradigm, genetics of lactase may not play a role. In studies reviewed, LI and LM were interchanged in several studies $[27,30,31,33,34,36,42]$ and Eadala introduced the concept of lactose sensitivity [24]. They reported the highest symptom rate of any study, independent of genetic analysis and with discrepant outcomes with BTs [24]. The reasons for these observations aren't clear and the study was criticized on methodological grounds [83]. This review in the end doesn't allow a true estimate of the frequency of LI in IBD patients. Activity of disease, site in CD and surgical resections variably affected outcome. The overall impression is that self reported LI along with counseling led to DF consumption restrictions.

\section{Health related effects of lactose/dairy foods in IBD}

Specific impact of milk and DFs consumption on IBD has not been studied as extensively as on other diseases (reviewed in [84]). In general there are 3 topics to consider: first is the relationship of DFs to risk of IBD, second DFs impact on IBD relapse rates, finally possible risks of dietary DFs restrictions.

While 2 epidemiological studies [50,51] suggested a positive correlation of increasing DFs intake with increasing incidence of IBD, remaining studies suggested possible protection by DFs [52-55] or no effect on IBD [56-59]. Further studies are needed to verify protective outcomes. However there is a hint that an ecological fallacy type relationship between DFs and IBD exists. In this situation, observed ecological relationships between disease and target variables are opposite to those expected at patient level studies. A similar paradigm occurs between DFs and colorectal cancer $[8,85]$.

The second topic that DFs aggravate established IBD is not clear. One study reported that milk and DFs intake were associated with flares [60] and this is supported in a study of food groups in patients with UC [86]. However in a large review, of effects of general diets in IBD, no convincing evidence was found to show that any nutrient induced flares [7]. The presence of IBS and role of FODMAPs contributing to symptoms may cloud the issue [82].

The third topic is whether DF restriction has any negative impacts. In the general population, an $\mathrm{NIH}$ conference on LI concluded that the main health hazard is the improper withdrawal of DFs. Benefits from DFs were stressed [87]. Among these, bone health, better control of hypertension [88], weight gain $[89,90]$ and a reduced risk for colorectal cancer either through calcium or vitamin D is oberved [91].

In IBD, osteopenia and osteoporosis are consequences of chronic inflammation and medications [92-94]. The role of calcium and DF intake in IBD-related bone disease is unclear [95-97] or controversial [98] but intuitively is still important.

Colorectal cancer is increased in IBD colitis and may be linked with chronic inflammation also [99]. Calcium and vitamin D may be protective both for cancer [100, 101] and provide anti-inflammatory effects [102].

Risks of cardiovascular complications may be increased in IBD [103] and calcium may contribute by reducing arterial stiffness [88]. Evaluation of the specific impact of DFs in IBD require further evaluation.

There are limitations to this review. Conclusions from meta-analyses are as accurate as the papers reviewed. Although the quality of most studies was rated as adequate, the period spans 50 years with the majority of studies being older. The period of study includes 4 modalities of lactase assessment and conceptual changes in the genetics of lactase as well as concepts related to symptoms. These variations, as well as inclusion of different populations, and the few number of studies may well account for heterogeneity. However, in the studies reviewed for metaanalysis patients were always studied in parallel with healthy controls, and the outcome sought was an objective prevalence of LM in IBD regardless of method of ascertainment. To our knowledge, this is the only review to date which derives conclusions based on the available literature.

\section{Summary and conclusions}

It is suggested that LM in IBD is determined by ethnicity in most cases of UC and CD. In CD small bowel involvement can produce secondary LM in LP. Although unproven, activity may also impact on LM. LM can aggravate LI but self reported LI or the overlap with FODMAP confound DFs specific role. Moreover there is emerging suggestive evidence that DFs may have benefits in IBD and restriction may impact unfavorably. Further work is needed to evaluate the role of DFs in IBD as well on methods to avoid their restriction.

\section{Acknowledgements}

We would like to thank Ms Linda van Inwegen for producing all the figures.

\section{Availability of data}

Tables and references within this article. There are no additional data.

\section{Authors' contributions \\ AS; Formulation of review, Review of the literature, Writing of MS, PG; Review of the literature, discussion of main papers content and approval to include in meta-analysis, participated in writing MS, XX; Statistical strategy, data analysis, writing of statistical methods and participated in writing of results, participated in correcting MS. All authors read and approved the final version of the MS.}

\section{Competing interests}

The authors declare that they have no competing interests.

Consent for publictaion

Not applicable. 


\section{Ethics approval}

Not applicable.

\section{Author details}

'Division of Gastroenterology, Department of Medicine, Jewish General Hospital, Room E-110,3755 Cote Ste Catherine Rd, Montreal, QC H3T 1E2, Canada. ${ }^{2}$ Department of Emergency Medicine, Jewish General Hospital, McGill University, Montreal, QC, Canada.

Received: 8 April 2016 Accepted: 29 June 2016

Published online: 13 July 2016

\section{References}

1. Kostic AD, Xavier RJ, Gevers D. The microbiome in inflammatory bowel disease: Current status and the future ahead. Gastroenterol. 2014;146:1489-99.

2. Wu GD, Chen J, Hoffmann C, Bittinger K, Chen YY, Keilbaugh SA, et al. Linking long-term dietary patterns with gut microbial enterotypes. Sci. 2011:334:105-8.

3. Albenberg LG, Wu GD. Diet and the intestinal microbiome: associations, functions, and implications for health and disease. Gastroenterol. 2014;146:1564-72.

4. D'Souza S, Levy E, Mack D, Israel D, Lambrette P, Ghadirlan P, et al. Dietary patterns and risk for Crohn'sdisease in children. Inflamm Bowel Dis. 2008;14:367-73.

5. Ananthakrishnan AN, Khalili H, Song M, Higuchi LM, Richter JM, Nimptsch K, et al. High School Diet and Risk of Crohn's Disease and Ulcerative Colitis. Inflamm Bowel Dis. 2015;21:2311-9.

6. Dixon LJ, Kabi A, Nickerson KP, McDonald C. Combinatorial effects of diet and genetics on inflammatory bowel disease pathogenesis. Inflamm Bowel Dis. 2015;21:912-22.

7. Spooren CE, Pierik MJ, Zeegers MP, Feskens EJ, Masclee AA, Jonkers DM. Review article: the association of diet with onset and relapse in patients with inflammatory bowel disease. Aliment Pharmacol Ther. 2013;38:1172-87.

8. Shrier I, Szilagyi A, Correa JA. Impact of lactose containing foods and the genetics of lactase on diseases: An analytical review of population data. Nutr Cancer. 2008;60:292-300.

9. Szilagyi A, Leighton H, Burstein B, Xue X. Latitude, sunshine, and human lactase phenotype distributions may contribute to geographic patterns of modern disease: the inflammatory bowel disease model. Clin Epidemiol. 2014;6:183-98

10. Mishkin S. Dairy sensitivity, lactose malabsorption, and elimination diets in inflammatory bowel disease. Am J Clin Nutr. 1997;65:564-7.

11. Savaiano DA, Boushey CJ, McCabe GP. Lactose intolerance symptoms assessed by meta-analysis: a grain of truth that leads to exaggeration. J Nutr. 2006;136:1107-13.

12. Matlik L, Savaiano D, McCabe G, VanLoan M, Blue CL, Boushey CJ. Perceived milk intolerance is related to bone mineral content in 10- to 13-year-old female adolescents. Pediatrics. 2007;120:e669-77.

13. Faure C, Giguere L. Functional gastrointestinal disorders and visceral hyprsensivity in children and adolescents suffering from Crohn's disease. Inflamm Bowel Dis. 2008;14:1569-74.

14. Vivinus-Nebot M, Frin-Mathy G, Bziouche H, Dainese R, Bernard G, Anty R, et al. Functional bowel symptoms in quiescent inflammatory bowel diseases: role of epithelial barrier disruption and low-grade inflammation. Gut. 2014;63:744-52.

15. Mishkin B, Yalovsky M, Mishkin S. Increased prevalence of lactose malabsorption in Crohn's disease patients at low risk for lactose malabsorption based ethnic origin. Am J Gastroenterol. 1997;92:1148-53.

16. Wells GA, Shea B, O'Connel D, Peterson J, Welch V, Losos M, et al. The Newcastle Ottawa Scale (NOS) for assessing the quality of nonrandomized studies in meta-analyses. Available at: http://www.ohri.ca/programs/clinical_ epidemiology/oxford.htm. Accessed 6th July 2016.

17. Moher D, Liberati A, Tetzlaff J. Altman DG, and the PRISMA Group. Preferred Reporting Items for Systematic Reviews and Meta-Analyses: The PRISMA Statement. Ann Intern Med. 2009;151:264-9.

18. Sweeting MJ, Sutton AJ, Lambert PC. What to add to nothing? Use and avoidance of continuity corrections in meta-analysis of sparse data. Stat Med. 2004;23:1351-75.

19. Higgins JPT, Thompson SG, Deeks JJ, Altman DG. Measuring inconsistency in meta analyses. BMJ. 2003;327:557-60.
20. Mantel N, Haenszel W. Statistical aspects of the analysis of data from retrospective studies of disease. J Natl Cancer Inst. 1959;22:719-48.

21. DerSimonian R, Laird N. Meta-analysis in clinical trials. Control Clin Trials. 1986;7:177-88.

22. Egger M, Davey Smith G, Schneider M, Minder C. Bias in meta-analysis detected by a simple, graphical test. BMJ. 1997;315:629-34.

23. Pena AS, Truelove SC. Hypolactasia and ulcerative colitis. Gastroenterol. 1973;64:400-4004.

24. Eadala P, Matthews SB, Waud JP, Geen JT, Campbell AK. Association of lactose sensitivity with inflammatory bowel disease - demonstrated by analysis of genetic polymorphism, breath gases and symptoms. Aliment Pharmacol Ther. 2011;34:735-46.

25. Barrett JS, Irving PM, Shepherd SJ, Muir JG, Gibson PR. Comparison of the prevalence of fructose and lactose malabsorption across chronic intestinal disorders. Aliment Pharmacol Ther. 2009:30:165-74.

26. Von Tirpitz C, Kohn C, Steinkamp M, Geerling I, Maier V, Moller P, et al. Lactose intolerance in active Crohn's disease, Clinical value of duodenal lactase analysis. J Clin Gastroenterol. 2002;34:49-53.

27. Bernstein CN, Ament M, Artinian L, Ridgeway J, Shanahan F. Milk tolerance in adults with ulcerative colitis. Am J Gastroeneterol. 1994;89:872-7.

28. Park RH, Duncan A, Russell Rl. Hypolactasia and Crohn's disease: a myth. Am J Gastroenterol. 1990;85:708-10.

29. Lobbley RW, Burrows PC, Warwick R, Dawson DJ, Holmes R Simultaneous assessment of intestinal permeability and lactose tolerance with orally administered raffinose, lactose and L-arabinose. Clin Sci. 1990;79:175-83

30. Kirschner BS, DeFavaro MV, Jensen W. Lactose malabsorption in children and adolescents with inflammatory bowel disease. Gastroenterol. 1981;81:829-32.

31. Tandon R, Mandell H, Spiro HM, Thayer WR. Lactose intolerance in Jewish patients with ulcerative colitis. Dig Dis. 1971;16:845-8.

32. Chalfin D, Holt PR. Lactase deficiency in ulcerative colitis, regional enteritis and viral hepatitis. Am J Dig Dis. 1967;12:81-7.

33. Gupta R, Makharia G, Khadgawat R, Yadav RK. Evaluation of lactose and milk intolerance and bone mineral density in Indian patients with inflammatory bowel disease. Natl Med J India. 2012;25:327-31.

34. Banos Madrid R, Salama Benerroch H, Moran Sanchez S, Gallardo Sanchez F, Albadalejo Merono A, La Mercader Martínez J. Lactose malabsorption in patients with inflammatory bowel disease without activity: would it be necessary to exclude lactose products in the diet of all patients. An Med Interna. 2004;21:212-4. Spa.

35. Ginard D, Riera J, Bonet L, Barranco L, Reyes J, Escarda A, et al. Lactose malabsorption in ulcerative colitis. A case - control study. Gastroenterol Hepatol. 2003;26:469-74. Spa.

36. Kochlar R, Mehta SK, Goenka MK, Mukherjee JJ, Rana SV, Gupta D. Lactose intolerance in idiopathic ulcerative colitis in north Indians. Indian J Med Res. 1993:98:79-82.

37. Pironi L, Callegari C, Ciornia GL, Lami F, Miglioti M, Barbara L. Lactose malabsorption in adult patients with Crohn's disease. Am J Gastroenterol. 1988;83:1267-71.

38. Ogata M, Yao T. Hypolactasia in Japanese Crohn's patients. Japn J Gastroenterol. 1992;89:2655-63. Jap.

39. Enattah NS, Kuokkanen M, Forsblom C, Natah S, Oksanen A, Jarvela I, et al. Correlation of intestinal disaccharidase activities with the C/T-13910 variant and age. World J Gastroenterol. 2007;13:3506-12.

40. Marton A, Xue X, Szilagyi A. Meta-analysis: The Diagnostic Accuracy of Lactose Breath Hydrogen or Lactose Tolerance Tests for Predicting the North European lactase polymorphism C/T - 13910.Alimentary. Pharmacol Ther. 2012;35:429-40.

41. Wiecke S, Wos H, Radziewicz-Winnick I, Komraus M, GryzbowskaChlebowczyk U. Disaccharidase activity in children with inflammatory bowel disease. Turk J Gastroenterol. 2014:25:185-91.

42. Huppe D, Tromm A, Langhorst H, May B. Lactose intolerance in chronic inflammatory bowel diseases. Dtsch Med Wochenschr. 1992;117:1550-5. Ger

43. Cabrera - Acosta GA, Milke - Garcia MP, Ramirez - Iglesias MT, Uscanga L. Deficient lactose digestion and intolerance in a group of patients with chronic nonspecific ulcerative colitis : a controlled, double blind, cross-over clinical trial. Rev Gastroenterol Mex. 2012;77:26-30.

44. Gudmand-Hoyer $E$, Jarnum S. Incidence and clinical significance of lactose malabsorption in ulcerative colitis. Gut. 1970;11:338-43. 
45. Busk HE, Dahlerup B, Lytzen T, Binder V, Gudmand-Hoyer E. The incidence of lactose malabsorption in ulcerative colitis. Scand J Gastroenterol. 1975;10:263-5.

46. Hessels J, Eidhof HHM, Steggink J, Roeloffzen WWH, Wu K, Tan G, et al. Assessment of hypolactasia and site - specific intestinal permeability by differential sugar absorption of raffinose, lactose, sucrose and mannitol. Clin Chem Lab Med. 2003;41:1056-63.

47. Dunne WT, Cooke WT, Allan RN. Enzymatic and morphometric evidence for Crohn's disease as a diffuse lesion of the gasrointestinal tract. Gut. 1977;18:290-4.

48. Newcomer AD, McGill DB. Incidence of lactase deficiency in ulcerative colitis. Gastroenterol. 1967;53:890-3.

49. Nolan-Clark D, Tapsell LC, Hu R, Han DY, Ferguson LR. Effects of dairy products on Crohn's disease symptoms are influenced by fat content and disease location but not lactose content or disease activity status in a New Zealand population. J Am Diet Assoc. 2011;1111:1165-72.

50. Kitahora T, Utsunomiya T, Yokota A. Epidemiological study of ulcerative colitis in Japan: incidence and familial occurrence. The Epidemiology Group of the Research Committee of Inflammatory Bowel Disease in Japan. J Gastroenterology. 1995;30 Suppl 8:5-8.

51. Shoda R, Matsueda K, Yamato S, Umeda N. Epidemiologic analysis of Crohn disease in Japan: increased dietary intake of $n-6$ polyunsaturated fatty acids and animal protein relates to the increased incidence of Crohn disease in Japan. Am J Clin Nutr. 1996;63:741-5.

52. Magee EA, Edmond LM, Tasker SM, Kong SC, Curno R, John H Cummings $\mathrm{JH}$. Associations between diet and disease activity in ulcerative colitis patients using a novel method of data analysis. Nutr J. 2005;4:7. doi:10.1186/1475-2891-4-7

53. Octoratou M, Merikas E, Malgarinos G, Stanciu C. Triantafillidis JKA prospective study of pre-illness diet in newly diagnosed patients with Crohn's disease. Rev Med Chir Soc Med Nat lasi. 2012;116:40-9.

54. Abubakar I, Myhill DJ, Hart AR, Lake IR, Harvey I, Rhodes JM, et al. A case-control study of drinking water and dairy products in Crohn's Disease-further investigation of the possible role of Mycobacterium avium paratuberculosis. Am J Epidemiol. 2007;165:776-83.

55. Opstelten JL, Leenders M, Dik VK, Chan SS, van Schaik FD, Khaw KT, et al. Dairy Products, Dietary Calcium, and Risk of Inflammatory Bowel Disease: Results From a European Prospective Cohort Investigation. Inflamm Bowel Dis. 2016;22(6):1403-11.

56. Jowett SL, Seal CJ, Pearce MS, Phillips E, Gregory W, Barton JR, et al. Influence of dietary factors on the clinical course of ulcerative colitis: a prospective cohort study. Gut. 2004;53:1479-84.

57. Jantchou P, Morois S, Clavel-Chapelon F, Boutron-Ruault MC, Carbonnel F. Animal protein intake and risk of inflammatory bowel disease: The E3N prospective study. Am J Gastroenterol. 2010;105:2195-201.

58. Reif S, Klein I, Lubin F, Farbstein M, Hallak A, Gilat T. Pre-illness dietary factors in inflammatory bowel disease. Gut. 1997:40(6):754-60.

59. Spehlmann ME, Begun AZ, Saroglou E, Hinrichs F, Tiemann U, Raedler A, et al. Risk factors in German twins with inflammatory bowel disease: results of a questionnaire-based survey. J Crohn's Colitis. 2012;6:29-42.

60. Joachim $\mathrm{G}$. The relationship between habits of food consumption and reported reactions to food in people with inflammatory bowel disease-testing the limits. Nutr Health. 1999;13:69-83.

61. Jowett SL, Seal CJ, Phillips E, Gregory W, Barton JR, Welfare MR. Dietary beliefs of people with ulcerative colitis and their effect on relapse and nutrient intake. Clin Nutr. 2004;23:161-70.

62. Brasil Lopes M, Rocha R, Castro Lyra A, Rosa Oliveira V, Gomes Coqueiro F, Silveira Almeida N, et al. Restriction of dairy products; a reality in inflammatory bowel disease patients. Nutr Hosp. 2014;29:575-81.

63. Vernia P, Loizos P, Di Giuseppantonio I, Amore B, Chiappini A, Canizzaro S. Dietary calcium intake in patients with inflammatory bowel disease. J Crohn's Colitis. 2014:8:312-7.

64. Andresen AFR. Ulcerative colitis- an allergic phenomenon. Am J Dig Dis. 1942:9:91-8

65. Binder JH, Gryboski JD, Thayer Jr WR, Spiro HM. Intolerance to milk in ulcerative colitis. A preliminary report. Am J Dig Dis. 1966;11:858-64.

66. Struthers Jr JE, Singleton JW, Kern Jr F. Intestinal lactase deficiency in ulcerative colitis and regional ileitis. Ann Intern Med. 1965;63:221-8.

67. Rana SV, Sharma S, Malik A, Kaur J, Prasad KK, Sinha SK, et al. Small intestinal bacterial overgrowth and orocecal transit time in patients with inflammatory bowel disease. Dig Dis Sci. 2013;58:2594-8.

68. Buning $C$, Ockenga JK, Krüger $S$, Jurga J, Baier $P$, Dignass $A$, et al. The C/C(-13910) and G/G9-22018) genotypes for adult-type hypolactasia are not associated with inflammatory bowel disease. Scand J Gastroenterol. 2003:38:538-42.

69. Elguezabal N, Chamorro S, Molina E, Garrido J, Izeta A, Rodrigo L, et al. Lactase persistence, NOD2 status and Mycobacterium avium subsp. Paratuberculosis infection associations to inflammatory bowel disease. Gut Pathogens. 2012;4:6.

70. Juste RA, Elquezabal N, Chamorro S, Molina E, Garrido JM, Riestra S, et al. Associations between CARD15 polymorphisms, MAPDNA in blood and lactase persistence in a Crohn's disease case-control study in north Spain, vol. 269. Minnesota: Proceedings of the 10th International Colloquim on Paratuberculosis; 2009. p. 9-14.

71. Nolan DJ, Han DY, Lam WJ, Morgan AR, Fraser AG, Tapsell LC, et al. Genetic adult lactase persistence is associated with risk of Crohn's disease in a New Zealand population. BMC Res Notes. 2010;3:339.

72. Murdoch TB, Bernstein CN, El-Gabalawy H, Stempak JM, Sargent M, Elias B, et al. Prevalence of genetic variants associated with inflammatory bowel disease in a healthy First Nations cohort. CMAJ. 2012;184:E435-441.

73. Gearry RB, Lea RA, Roberts RL, Chambers GK, Barclay ML, Kennedy MA CARD 15 allele frequency differences in New Zealand Maori: ancestry specific susceptibility to Crohn's disease in New Zealand. Gut. 2006;55:580.

74. Yang J, Fox M, Cong Y, Chu H, Zheng X, Long Y, et al. Lactose intolerance in irritable bowel syndrome patients with diarrhoea: the roles of anxiety, activation of the innate mucosal immune system and visceral sensitivity. Aliment Pharmacol Ther. 2014;39:302-11.

75. Farup PG, Monsbakken KW, Vandvik PO. Lactose malabsorption in a population with irritable bowel syndrome: prevalence and symptoms. A case-control study. Scand J Gastroenterol. 2004;39:645-9.

76. Hertzler SR, Savaiano DA. Colonic adaptation to daily lactose feeding in lactose maldigesters reduces lactose intolerance. Am J Clin Nutr. 1996;64:232-6.

77. He T, Venema K, Priebe MG, Welling GW, Brummer RJ, Vonk RJ. The role of colonic metabolism in lactose intolerance. Eur J Clin Invest. 2008;38(8):541-7. doi:10.1111/j.1365-2362.2008.01966.x.

78. Windey K, Houben E, Deroover L, Verbeke K. Contribution of Colonic Fermentation and Fecal Water Toxicity to the Pathophysiology of Lactose-Intolerance. Nutrients. 2015;7:7505-22. doi:10.3390/nu7095349.

79. Szilagyi A, Rivard J, Shrier I. Diminished efficacy of colonic adaptation to lactulose occurs in patients with inflammatory bowel disease in remission. Dig Dis Sci. 2002;47:2811.

80. Gibson PR, Shepperd J. Personal view: food for thought - western lifestyle and susceptibility to Crohn's disease. The FODMAP hypothesis. Aliment Pharmacol Ther. 2005;21:1399-409.

81. Gearry RB, Irving PM, Barrett JS, Nathan DM, Shepherd SJ, Gibson PR. Reduction of dietary poorly absorbed short-chain carbohydrates (FODMAPs) improves abdominal symptoms in patients with inflammatory bowel disease-a pilot study. J Crohns Colitis. 2009;3:8-14.

82. Halpin SJ, Ford AC. Prevalence of symptoms meeting criteria for irritable bowel syndrome in inflammatory bowel disease: systematic review and meta-analysis. Am J Gastroenterol. 2012;107:1474-82.

83. Garg M, Gibson PR. Lactose intolerance in inflammatory bowel disease. Aliment Pharmacol Ther. 2011;34:1140-1.

84. Szilagyi A. Adaptation to Lactose in Lactase Non Persistent People: Effects on Intolerance and the Relationship between Dairy Food Consumption and Evaluation of Diseases. Nutrients. 2015;7:6751-79.

85. Szilagyi A, Nathwani U, Vinokuroff C, Correa JA, Shrier I. The effect of lactose maldigestion on the relationship between dairy food intake and colorectal cancer: a systematic review. Nutr Cancer. 2006;55:141-50.

86. Bueno-Hernández N, Núñez-Aldana M, Ascaño-Gutierrez I, YamamotoFurusho JK. Evaluation of diet pattern related to the symptoms of Mexican patients with Ulcerative Colitis (UC): through the validity of a questionnaire. Nutr J. 2015;14:25. doi:10.1186/s12937-015-0014-3.

87. Suchy FJ, Brannon PM, Carpenter TO, Fernandez JR, Gilsanz V, Gould JB, et al. National institute of health consensus development conference: lactose intolerance in health. Ann Intern Med. 2010;152:792-6.

88. Lovegrove JA, Hobbs DA. Plenary Lecture 2: Milk and dairy produce and CVD: new perspectives on dairy and cardiovascular health. Proc Nutr Soc. 2016;24:1-12.

89. Abargouei AS, Janghorbani M, Salehi-Marzijarani M, Esmaillzadeh A. Effect of dairy consumption on weight and body composition in adults: a systematic review and meta-analysis of randomized controlled clinical trials. Int J Obesity. 2012;36:1485-93.

90. Lu L, Xun P, Wan Y, He K, Cai W. Long-term association between dairy consumption and risk of childhood obesity: a systematic review and meta-analysis of prospective cohort studies. Eur J Clin Nutr. 2016;70:414-23. 
91. Aune D, Lau R, Chan DS, Vieira R, Greenwood DC, Kampman E, et al. Dairy products and colorectal cancer risk: A systematic review and meta-analysis of cohort studies. Ann Oncol. 2012;23:37-45.

92. Takayanagi H. Osteoimmunology: shared mechanisms and crosstalk between the immune and bone systems. Nat Rev Immun. 2007;7:292-304.

93. Ali T, Lam D, Bronze MS, Humphrey MB. Osteoporosis in inflammatory bowel disease. Am J Med. 2009;122:599-604.

94. Lima CA, Lyra AC, Rocha R, Santana GO. Risk factors for osteoporosis in inflammatory bowel disease patients. World J Gastrointest Pathophysiol. 2015;6:210-8.

95. Bernstein CN, Bector S, Leslie WD. Lack of relationship of calcium and vitamin $\mathrm{D}$ intake to bone mineral density in premenopausal women with inflammatory bowel disease. Am J Gastroenterol. 2003;98:2468-73.

96. Bernstein CN, Seeger LL, Anton PA, Artinian L, Geffrey S, Goodman W, et al. A randomized, placebo-controlled trial of calcium supplementation for decreased bone density in corticosteroid-using patients with inflammatory bowel disease: a pilot study. Aliment Pharmacol Ther. 1996;10:777-86.

97. Silvennoinen J, Lamberg-Allardt C, Kärkkäinen M, Niemelä S, Lehtola J. Dietary calcium intake and its relation to bone mineral density in patients with inflammatory bowel disease. J Intern Med. 1996;240:285-92.

98. Targownik LE, Bernstein CN, Nugent Z, Leslie WD. Inflammatory bowel disease has a small effect on bone mineral density and risk for osteoporosis. Clin Gastroenterol Hepatol. 2013;11:278-85.

99. Hartnett L, Egan LJ. Inflammation, DNA methylation and colitis-associated cancer. Carcinogenesis. 2012;33:723-31.

100. Cho E, Smith-Warner SA, Spiegelman D, Beson WL, van den Brandt PA, et al. Dairy foods, calcium and colorectal cancer: a pooled analysis of 10 cohort studies. J Nat Cancer Inst. 2004;96:1015-22.

101. Ananthakrishnan AN, Cheng SC, Cai T, Cagan A, Gainer VS, Szolovits P, et al. Association between reduced plasma 25-hydroxy vitamin $D$ and increased risk of cancer in patients with inflammatory bowel diseases. Clin Gastroenterol Hepatol. 2014;12:821-7.

102. Schepens MA, Schonewille AJ, Vink C, van Schothorst EM, Kramer E, Hendriks T, et al. Supplemental calcium attenuates the colitis-related increase in diarrhea, intestinal permeability, and extracellular matrix breakdown in HLA-B27 transgenic rats. J Nutr. 2009;139:1525-33.

103. Schicho R, Marsche G, Storr M. Cardiovascular complications in inflammatory bowel disease. Curr Drug Targets. 2015;16:181-8.

\section{Submit your next manuscript to BioMed Central and we will help you at every step:}

- We accept pre-submission inquiries

- Our selector tool helps you to find the most relevant journal

- We provide round the clock customer support

- Convenient online submission

- Thorough peer review

- Inclusion in PubMed and all major indexing services

- Maximum visibility for your research

Submit your manuscript at wuw biomedcentral.com/submit

C Biomed Central 